\title{
Resource limitations and competitive interactions affect carnivore community composition at different ecological scales in a temperate island system
}

https://doi.org/10.1515/mammalia-2017-0162

Received November 30, 2017; accepted January 15, 2019; previously published online March 8, 2019

Abstract: Selective pressures (i.e. resource limitation and competitive interaction) that drive the composition of ecological communities vary, and often operate on different ecological scales (ecological variables across varying spatial scales) than observed patterns. We studied the drivers of distribution and abundance of the American marten (Martes americana) and the carnivore community at three ecological scales on a Great Lakes island archipelago using camera traps. We found different drivers appeared important at each ecological scale and studying any of the three scales alone would give a biased understanding of the process driving the system. Island biogeography (resource limitation) was most important for carnivore richness, with higher richness on larger islands and lower richness as distance from the mainland increased. Marten presence on individual islands appeared to be driven by island size (resource limitation) and human avoidance (competitive interaction). Marten abundance at camera trap sites was driven by the cascading effect of coyotes (Canis latrans) on fishers (Pekania pennanti) (competitive interaction). Incorporating three ecological scales gave novel insights into the varying effects of resource limitation and competitive interaction processes. Our data suggests that ecological communities are structured through multiple competing ecological forces, and effective management

\footnotetext{
*Corresponding author: Maximilian L. Allen, Illinois Natural History Survey, University of Illinois, 1816 S. Oak Street, Champaign, IL 61820, USA, e-mail: maxallen@illinois.edu. https://orcid. org/0000-0001-8976-889X

Rachel E. Harris, Lucas 0. Olson and Timothy R. Van Deelen: Department of Forest and Wildlife Ecology, University of Wisconsin, Madison, WI, USA

Erik R. Olson: Natural Resources, Northland College, 1411 Ellis Ave S, Ashland, WI 54806, USA

Julie Van Stappen: Planning and Resource Management, Apostle Islands National Lakeshore, 415 Washington Ave, Bayfield, WI 54814, USA
}

and conservation relies on our ability to understand ecological forces operating at multiple ecological scales.

Keywords: American marten; camera trap; carnivores; community ecology; island biogeography; Martes americana; scale.

\section{Introduction}

Understanding the effect of scale is essential to determining the drivers of distribution, abundance, and diversity of species within and among ecological communities (Levin 1992, Ruggiero et al. 1994). However, ecological patterns are often driven by ecological processes that operate on different spatial scales (Levin 1992). The selective pressures that affect a meta-community may be different than those that affect a local community, species or individual (Levin 1992, Leibold et al. 2004). The diversity and structure of ecological communities are usually driven by varying combinations of resource limitations and competitive interactions (Hairston et al. 1960, Power 1992), however, one process can outweigh the other depending on the ecological scale (ecological variables across varying spatial scales) at which it is studied (Levin 1992). It is therefore important to determine the factors that affect distribution and abundance of species and communities at multiple ecological scales.

Resource limitations and competitive interactions structure ecological communities differently. Resource limitation processes include ecosystem productivity, which often dictates the availability of food and other resources (Hairston et al. 1960, Oksanen and Oksanen 2000), which are often a limiting factor for populations (Power 1992, Carlson et al. 2014). Competitive interaction processes include direct and indirect competition (Emerson and Gillespie 2008, Levi and Wilmers 2012), where intra- and inter-specific competition structure communities through competition over resources and the ability to exploit niches (Hairston et al. 1960, Emerson and Gillespie 2008). Carnivores also structure the distribution 
and abundance of subordinate species in ecological communities through predation and the fear of predation (Brown et al. 1999, Levi and Wilmers 2012).

Island biogeography is a resource limiting process that affects the availability of resources, species diversity and abundance. Island biogeography has shown that the size and isolation of islands affects both abundance and richness of species, as well as immigration and extinction rates (MacArthur and Wilson 1967, Simberloff 1974, Whittaker and Fernandez-Palacius 2007). However, to date there have been limited studies of the effects of island biogeography on either temperate inland communities or complex mammalian species. Most studies of island biogeography have occurred in tropical systems with innately high levels of biodiversity that are concentrated at lower trophic levels (Whittaker and Fernandez-Palacius 2007), with few studies that focus on temperate or inland systems. Temperate inland systems may be affected by island biogeography differently than tropical systems, due to lower levels of diversity and other factors, such as seasonal effects, that can increase stochasticity and variation in temperate ecological communities (Leibold et al. 2004). Factors affecting the distribution and abundance of species that occupy higher trophic levels, including carnivores, can also be more complex (Ripple et al. 2014).

Carnivores are complex species that are important for maintaining ecological function in communities (Estes et al. 2011, Ripple et al. 2014), but whose populations can be affected by many factors. Carnivores tend to have low population densities (Ripple et al. 2014), and their populations and behaviors can be affected by availability of preferred habitat and prey abundance (Carlson et al. 2014, Ripple et al. 2014). They are also affected by sympatric competition with other carnivores that exploit similar food resources and ecological niches (Hairston et al. 1960, Levi and Wilmers 2012). This is especially important for smaller carnivores that attempt to use areas with abundant prey while simultaneously avoiding areas frequently used by dominant sympatric competitors (Lesmesiter et al. 2015, Wang et al. 2015). The complexity of these interactions is highlighted by cascading effects within the carnivore community, where apex carnivores release subordinate small carnivores from competitive pressure by reducing the abundance of dominant mesocarnivores either in the system (Levi and Wilmers 2012) or at a particular resource (Allen et al. 2015).

Our focal species was the American marten (Martes americana, Turton, 1806). American martens are a small, opportunistic carnivore which are state-endangered in Wisconsin (Woodford and Dumyham 2011, Allen et al. 2018b). Shrews (Blarina sp., Sorex sp.), lagomorphs
(Leporidae spp.), and White-tailed deer (Odocoileus virginianus (Zimmermann, 1780)) carrion compose a major portion of Martens diet (Zielinski and Duncan 2004, Carlson et al. 2014). They are habitat specialists associated with mature northern forests and are of cultural importance to the Ojibwe tribes native to the area (Allen et al. 2018b). Martens were found recently within the Apostle Islands National Lakeshore (APIS) after 50 years of apparent absence (Allen et al. 2018b), prompting questions about their abundance and distribution throughout the system.

We deployed camera traps over 2 years on 13 islands within the Apostle Islands National Lakeshore to document carnivore distribution and abundance. Our objectives were to determine the drivers of distribution and abundance of martens and the carnivore community in a Great Lakes island archipelago. We used an a-priori modeling framework to use our knowledge of the system to test biologically relevant hypotheses at three different ecological scales in order to understand the dynamics of carnivores and martens in the system. Our specific objectives were to: (1) determine the drivers of carnivore richness among different islands; (2) determine the drivers of marten presence and absence among different islands; (3) determine the drivers of marten abundance at each camera trap site. We considered potential drivers including competitive interactions with larger carnivores and resource limitation in the form of preferred habitat and prey availability at each scale. Testing the drivers of the abundance and distribution of the carnivore community in a temperate island system at multiple scales has the potential for novel insights into the varying effects of resource limitation and competitive interaction processes, including island biogeography and cascading effects.

\section{Materials and methods}

\section{Study area}

The Apostle Islands are an archipelago of Pleistocene relict sandstone islands located in southwestern Lake Superior, WI, USA. APIS was established in 1970, protecting 21 of the 22 islands. The archipelago is in the transition zone between northern boreal coniferous forest and deciduous forest, creating diverse vegetative structure (Judziewicz and Koch 1993). Microclimatic conditions and vegetative communities are variable between islands depending on the island size, elevation and location 
within Lake Superior (Judziewicz and Koch 1993; Supplementary material 1). The average temperature for the duration of this study was $4.4^{\circ} \mathrm{C}$, with minimum and maximum temperatures ranging from $-30.0^{\circ} \mathrm{C}$ to $32.8^{\circ} \mathrm{C}$, and mean annual precipitation was $82.8 \mathrm{~cm}$ of rainfall and $197.4 \mathrm{~cm}$ of snowfall (Allen et al. 2018a). Ice cover in the Bayfield harbor, which is indicative of overall lake trends, has decreased about 3 days/decade over the past 150 years (Howk 2009), and the ice season has begun an average of 11.7 days later and ended 3.0 days earlier every decade since 1975 (Howk 2009).

\section{Field methods}

We systematically deployed 91 camera traps (Hyperfire Model, Reconyx, Holmen, WI, USA) on APIS beginning in September 2014 and ending in June 2016, but four of our camera traps did not function and we excluded them from our analyses. To choose target deployment sites, we overlaid a $1 \mathrm{~km}^{2}$ grid on satellite imagery of the islands and placed target locations at the center of cells with $>50 \%$ of surface area on land. On Stockton Island, four deployment locations were randomly omitted due to a shortage of camera traps. In subsequent camera deployments, we adjusted camera trap density $\left(y\right.$, cameras $\left./ \mathrm{km}^{2}\right)$ using a power law curve based on island size $\left(x, \mathrm{~km}^{2}\right)$ to ensure smaller islands were surveyed more intensively. We used the following power law curve equation:

$$
y=2.0826 x^{-0.369}
$$

On Oak Island, two camera trap locations were omitted according to our power law curve for camera trap density. We omitted one location that was in an area of high human use and a second location due to access issues (e.g. steep ravine). For some of the smaller islands (i.e. Cat, Devils, Ironwood, Raspberry and North Twin) we relaxed our $>50 \%$ of grid cell surface area on land to ensure adequate camera trap densities.

We used standardized procedures and targeted finescale landscape features to maximize detections of carnivores (i.e. camera trap height, orientation, focal area structure) while placing camera traps (O'Connell et al. 2011). From each target deployment location, we walked concentric circles until we intersected animal sign, a clearing, trail or other site with above-average probability of capturing large mammals. We typically selected more open areas that contained a downed tree with few branches. We set the camera traps $0.75-1 \mathrm{~m}$ off the ground and 3-7 m away from the chosen site, and programmed camera traps to take a series of 3-5 photos when they detected motion and no refractory period between trigger events. On each island, we randomly assigned a lure treatment to half of the camera trap sites for that island. These sites received a commercial predator trapping scent lure (Caven's Gusto, Minnesota Trapline Products Inc., Pennock, MN, USA) during the first 6-month deployment, and later we rotated sites and all previously non-lured sites received lure during the second 6-month deployment. Effectively, scent lure was present at half of sites in any given season to account for seasonal variation in detection. We placed aerial call lures $(\sim 3-4 \mathrm{~m})$ and local lures (on downed woody vegetation) to draw carnivores into the camera traps detection area. We returned to each camera trap at approximately 6-month intervals to replace batteries and memory cards. We measured habitat variables which may influence carnivore communities through spatial data layers in a GIS (ArcMap 10.3; ESRI 2014). Vegetative characteristics were calculated within a $100 \mathrm{~m}$ buffer around each camera site using an open access data layer, Wiscland 2.0 (Wiscland 2016). Within each buffer, we calculated the proportion of the habitat that was composed of pine, mixed hardwood, and northern hardwood (see Wiscland 2.0 user guide for classification details).

\section{Statistical analyses}

We used program $R$ version 3.3.1 (R Core Team 2016) for all of our statistical analyses. To calculate total trap nights, we first determined if a camera trap was fully operational for the duration of its deployment. Based on natural breaks in the distribution of days between capture events, if a camera trap did not take a photo in $>28$ days we assumed that it malfunctioned due to low battery power or extreme temperatures, and these periods were excluded from our calculations. If the camera trap resumed taking multiple photos after a $>28$-day period of no detections, we considered it reactivated.

We defined a photo event as any series of photos (as programmed) triggered by a human or wildlife species. To avoid pseudo-replication, we considered consecutive photo captures of the same species within $30 \mathrm{~min}$ to be the same event (Naing et al. 2015, Wang et al. 2015). We totaled the number of independent events $(E)$ for each species, and determined their relative abundance $(R A)$ at each camera trap as:

$$
R A=(E / T N) \times 100
$$

where $T N$ is the total number of trap nights that the camera trap was operational. We calculated carnivore 
species richness as the number of terrestrial carnivores documented on a given island.

We used a series of a-priori generalized linear models (GLMs) with standardized variables (Table 1), using a suite of models to understand the drivers of three dependent variables at different scales: carnivore richness at the island level, marten presence/absence at the island level, and marten abundance at the site level. We compared models using Akaike information criterion (AIC) weight, using AICc values in each of our models due to low sample sizes (Burnham and Anderson 2002). When interpreting models we considered any model with $\triangle$ AIC $<2$ to have substantial support and any model with $\triangle \mathrm{AIC}<4$ to be biologically relevant (Burnham and Anderson 2002).

Table 1: Individual variables considered in creating a-priori models of carnivore richness, marten presence, and marten abundance on the Apostle Island National Lakeshore, WI, USA.

\begin{tabular}{|c|c|c|}
\hline Name & Symbol & Description \\
\hline Bobcat abundance & $\mathrm{BCAB}$ & RA of bobcats at camera trap site \\
\hline Coyote abundance & CYAB & RA coyotes at camera trap site \\
\hline Deer abundance & DEAB & RA of deer at camera trap site \\
\hline Elevation & ELEV & $\begin{array}{l}\text { The maximum elevation }(\mathrm{m}) \text { of } \\
\text { the island }\end{array}$ \\
\hline Fisher abundance & FIAB & RA of fishers at camera trap site \\
\hline $\begin{array}{l}\text { Gray wolf } \\
\text { abundance }\end{array}$ & GWAB & $\begin{array}{l}\text { RA of gray wolves at camera trap } \\
\text { site }\end{array}$ \\
\hline Hardwood habitat & HAHA & $\begin{array}{l}\text { Area of hardwood habitat within } \\
100 \mathrm{~m} \text { radius }\end{array}$ \\
\hline Human abundance & HUAB & RA of people at camera trap site \\
\hline $\begin{array}{l}\text { Inter-island } \\
\text { distance }\end{array}$ & ISDI & $\begin{array}{l}\text { Distance to the nearest island } \\
(\mathrm{km})\end{array}$ \\
\hline Island size & ISSZ & Total area of the island $\left(\mathrm{km}^{2}\right)$ \\
\hline $\begin{array}{l}\text { Lagomorph } \\
\text { abundance }\end{array}$ & LGAB & $\begin{array}{l}\text { RA of lagomorphs at camera trap } \\
\text { site }\end{array}$ \\
\hline $\begin{array}{l}\text { Mean coyote } \\
\text { abundance }\end{array}$ & MCAB & $\begin{array}{l}\text { Mean RA coyotes across camera } \\
\text { trap sites on island }\end{array}$ \\
\hline $\begin{array}{l}\text { Mean fisher } \\
\text { abundance }\end{array}$ & MFAB & $\begin{array}{l}\text { Mean RA of fishers across camera } \\
\text { trap sites on island }\end{array}$ \\
\hline $\begin{array}{l}\text { Mean human } \\
\text { abundance }\end{array}$ & MHAB & $\begin{array}{l}\text { Mean RA of people across camera } \\
\text { trap sites on island }\end{array}$ \\
\hline $\begin{array}{l}\text { Mixed hardwood } \\
\text { habitat }\end{array}$ & MIHA & $\begin{array}{l}\text { Area of mixed hardwood habitat } \\
\text { within } 100 \mathrm{~m} \text { radius }\end{array}$ \\
\hline Mainland distance & MLDI & Distance to mainland Wisconsin \\
\hline Mean trap nights & MTRP & $\begin{array}{l}\text { Mean number of trap nights } \\
\text { across camera traps on island }\end{array}$ \\
\hline Pine habitat & PIHA & $\begin{array}{l}\text { Area of pine habitat within } 100 \mathrm{~m} \\
\text { radius }\end{array}$ \\
\hline Red fox abundance & RFAB & RA of red foxes at camera trap site \\
\hline Squirrel abundance & SQAB & RA of squirrels at camera trap site \\
\hline Trap nights & TRAP & $\begin{array}{l}\text { Number of trap nights at camera } \\
\text { trap site }\end{array}$ \\
\hline
\end{tabular}

RA, relative abundance.
To determine the drivers of carnivore richness at the island level we tested among seven a-priori models (Table 2). We used a Gaussian GLM with an identity link for each model, with the richness of carnivores as our dependent variable. To determine the drivers of marten presence/absence at the island level we tested among six a-priori models (Table 2). We used a binomial GLM with a logit link for each model, with whether martens were detected on a given island as our dependent variable. To determine the drivers of marten abundance at the site level we tested among seven a-priori models (Table 2). We used zero-inflated Poisson (ZIP) models in the pscl package (Zeileis et al. 2008, Jackman 2015), because ZIP models effectively account for the presence of non-informative, structural zeros in a binomial model followed by a Poisson model with non-informative zeros accounted for. We held trap nights and island size constant as predictors of non-informative zeros in the binomial process, and changed the variables as noted in Table 2 for each model in the Poisson process.

\section{Results}

We had 87 functioning camera traps, with a mean of 6.7 $( \pm 2.3 \mathrm{SE})$ camera traps per island (range $=1-30$ ), and our density averaged $1.23( \pm 0.19 \mathrm{SE}$, range $=0.74-3.08)$ functioning camera traps $/ \mathrm{km}^{2}$. We collected 93,515 photographs (not including time-lapse photographs) across 18,761 trap nights. This included 3592 wildlife events, of which 1076 were carnivore events. We documented 88 marten events on five of 13 islands (Figure 1). We detected 13 other mammal species or groups, including black bear (Ursus americanus (Pallas, 1780)), bobcat (Lynx rufus (Schreber, 1777)), coyote (Canis latrans (Say, 1823)), fisher (Pekania pennanti (Erxleben, 1777)), gray fox (Urocyon cinereoargenteus (Schreber, 1775)), lagomorphs, common raccoon (Procyon lotor (L., 1758)), red fox (Vulpes vulpes (L., 1758)), squirrels (Sciuridae spp.), weasels (Mustela spp.), whitetailed deer and gray wolf (Canis lupus (L., 1758)). The most commonly detected classifications were squirrels $(\mathrm{n}=1506)$, black bears $(\mathrm{n}=581)$ and lagomorphs $(\mathrm{n}=359)$, while the least common were raccoons $(\mathrm{n}=5)$ and weasels $(\mathrm{n}=1)$ (Supplementary material 2).

Our top model for carnivore richness (Figure 1), Immigration Island Biogeography $\left({ }_{w} \mathrm{AIC}_{\mathrm{c}}=0.57\right)$, had twice as much support as any other model to explain the distribution of carnivore richness among islands (Table 3). Among the variables in the model, island size had a positive coefficient $(~(B=0.19)$, while distance to mainland had a negative 


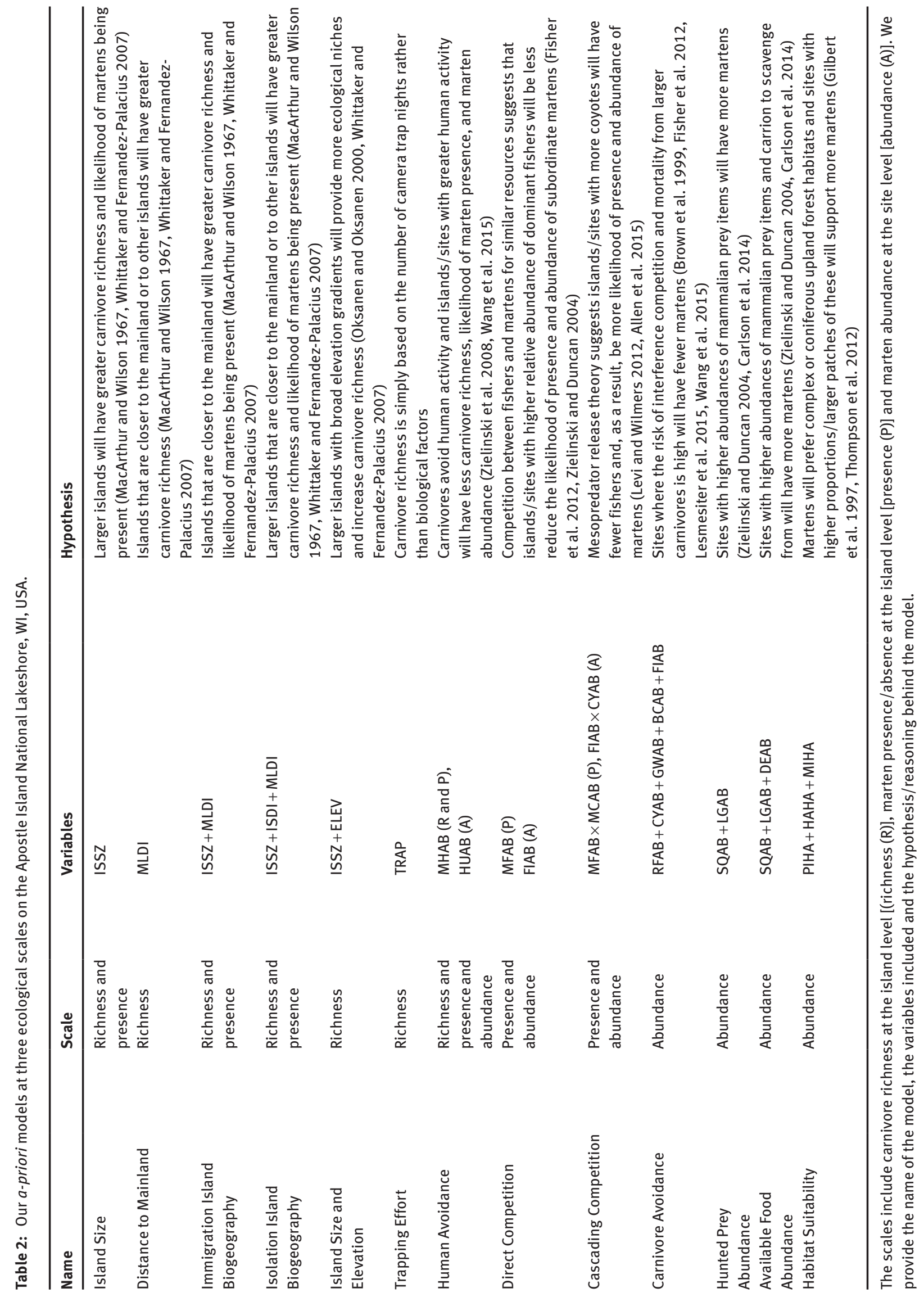



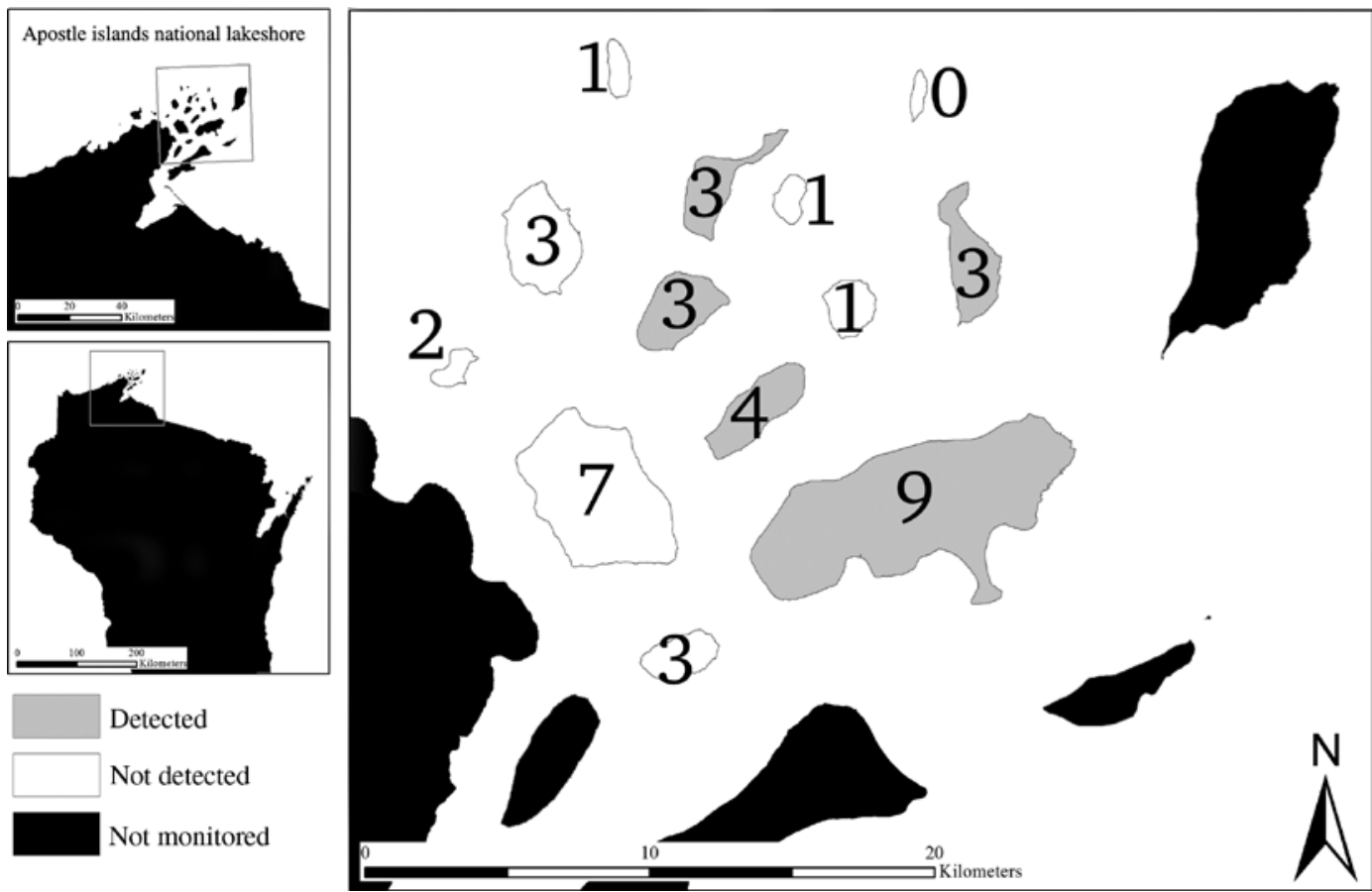

Figure 1: The carnivore richness (indicated by the number associated with an island) and the presence/absence of American martens (indicated by shaded or not for each island) on the Apostle Islands National Lakeshore, WI, USA from September 2014 to June 2016.

Table 3: Results of our model comparisons of carnivore richness at the island level, marten presence/absence at the island level, and marten abundance at the site level, with individual models ranked based on their $\mathrm{AIC}_{\mathrm{w}}$.

\begin{tabular}{|c|c|c|c|c|}
\hline Model name & $\mathrm{AIC}_{\mathrm{c}}$ & $\triangle \mathrm{AIC}$ & ${ }_{w} \mathrm{AIC}_{\mathrm{c}}$ & Cumulative $_{w} \mathrm{AIC}_{\mathrm{c}}$ \\
\hline \multicolumn{5}{|l|}{ Carnivore richness } \\
\hline Immigration Island Biogeography & 39.29 & 0.00 & 0.58 & 0.58 \\
\hline Island Size and Elevation & 40.85 & 1.56 & 0.27 & 0.85 \\
\hline Island Size & 42.95 & 3.66 & 0.09 & 0.94 \\
\hline Isolation Island Biogeography & 43.85 & 4.56 & 0.06 & 1.00 \\
\hline Distance to Mainland & 63.48 & 24.19 & 0.00 & 1.00 \\
\hline Trapping Effort & 63.64 & 24.36 & 0.00 & 1.00 \\
\hline Human Avoidance & 68.02 & 28.74 & 0.00 & 1.00 \\
\hline \multicolumn{5}{|l|}{ Marten presence/absence } \\
\hline Island Size & 21.01 & 0.00 & 0.36 & 0.36 \\
\hline Human Avoidance & 21.07 & 0.16 & 0.33 & 0.69 \\
\hline Direct Competition & 22.52 & 1.51 & 0.17 & 0.86 \\
\hline Immigration Island Biogeography & 23.72 & 2.71 & 0.09 & 0.96 \\
\hline Isolation Island Biogeography & 25.48 & 4.47 & 0.04 & 0.99 \\
\hline Cascading Competition & 29.30 & 8.28 & 0.01 & 1.00 \\
\hline \multicolumn{5}{|l|}{ Marten abundance } \\
\hline Cascading Competition & 246.88 & 0.00 & 0.53 & 0.53 \\
\hline Human Avoidance & 248.09 & 1.21 & 0.29 & 0.83 \\
\hline Hunted Prey Abundance & 250.61 & 3.74 & 0.08 & 0.91 \\
\hline Available Food Abundance & 251.77 & 4.90 & 0.05 & 0.95 \\
\hline Habitat Suitability & 252.63 & 5.76 & 0.03 & 0.98 \\
\hline Direct Competition & 254.66 & 7.78 & 0.01 & 0.99 \\
\hline Carnivore Avoidance & 256.08 & 9.20 & 0.01 & 1.00 \\
\hline
\end{tabular}




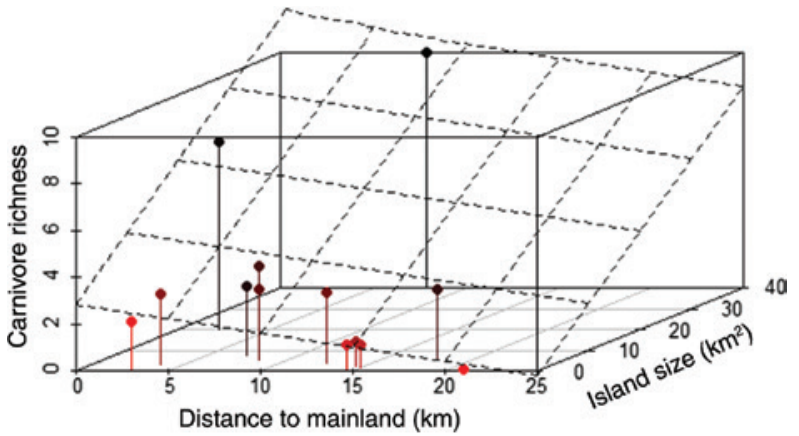

Figure 2: The effects of "Immigration Island Biogeography" (island size and distance from mainland) on carnivore richness on the Apostle Islands National Lakeshore, WI, USA from September 2014 to June 2016.

coefficient $(\beta=-0.11)$ (Figure 2). Our second-best model, Island Size and Elevation $\left({ }_{\mathrm{w}} \mathrm{AIC}_{\mathrm{c}}=0.26, \beta_{\text {island size }}=0.17\right.$, $\beta_{\text {elevation }}=0.02$ ), also had substantial support, while our Island Size Model ( $\left.{ }_{\mathrm{w}} \mathrm{AIC}_{\mathrm{c}}=0.09, \beta=0.22\right)$ was biologically relevant.

Our top models for marten presence (Figure 1) at the island level were Island Size $\left({ }_{w} \mathrm{AIC}_{\mathrm{c}}=0.36, \beta=0.07\right)$ and Human Avoidance ( ${ }_{w} \mathrm{AIC}_{\mathrm{c}}=0.33, \beta=-0.49$ ) (Table 3).
Direct competition $\left({ }_{w} \mathrm{AIC}_{\mathrm{c}}=0.17, \beta=-0.01\right)$ also had substantial support, while Immigration Island Biogeography was biologically relevant ${ }_{\mathrm{w}} \mathrm{AIC}_{\mathrm{c}}=0.09, \beta_{\text {island size }}=0.10$, $\beta_{\text {mainland distance }}=0.10$ ).

Our top model for marten abundance at the site level (Figure 3), Cascading Competition $\left({ }_{w} \mathrm{AIC}_{c}=0.53\right)$, had nearly twice as much support as any other model to explain the abundance of martens at camera trap sites (Table 3). In this model, both coyotes and fishers had negative coefficients for marten abundance $\left(\beta_{\text {coyote }}=-0.18\right.$, $\beta_{\text {fisher }}=-1.60$ ), but their interaction had a stronger positive coefficient $(\beta=8.59)$. Our second-best model, Human Avoidance ( ${ }_{w} \mathrm{AIC}_{c}=0.29, \beta=-1.51$ ), also had substantial support, while Hunted Prey Abundance $\left({ }_{w} \mathrm{AIC}_{c}=0.08\right.$, $\beta_{\text {squirrel }}=0.02, \beta_{\text {lagomorph }}=-0.03$ ) was biologically relevant.

\section{Discussion and conclusion}

Our study showed that different processes appeared important at each scale tested and highlights the importance of understanding the drivers of the distribution and abundance of wildlife populations at multiple ecological scales

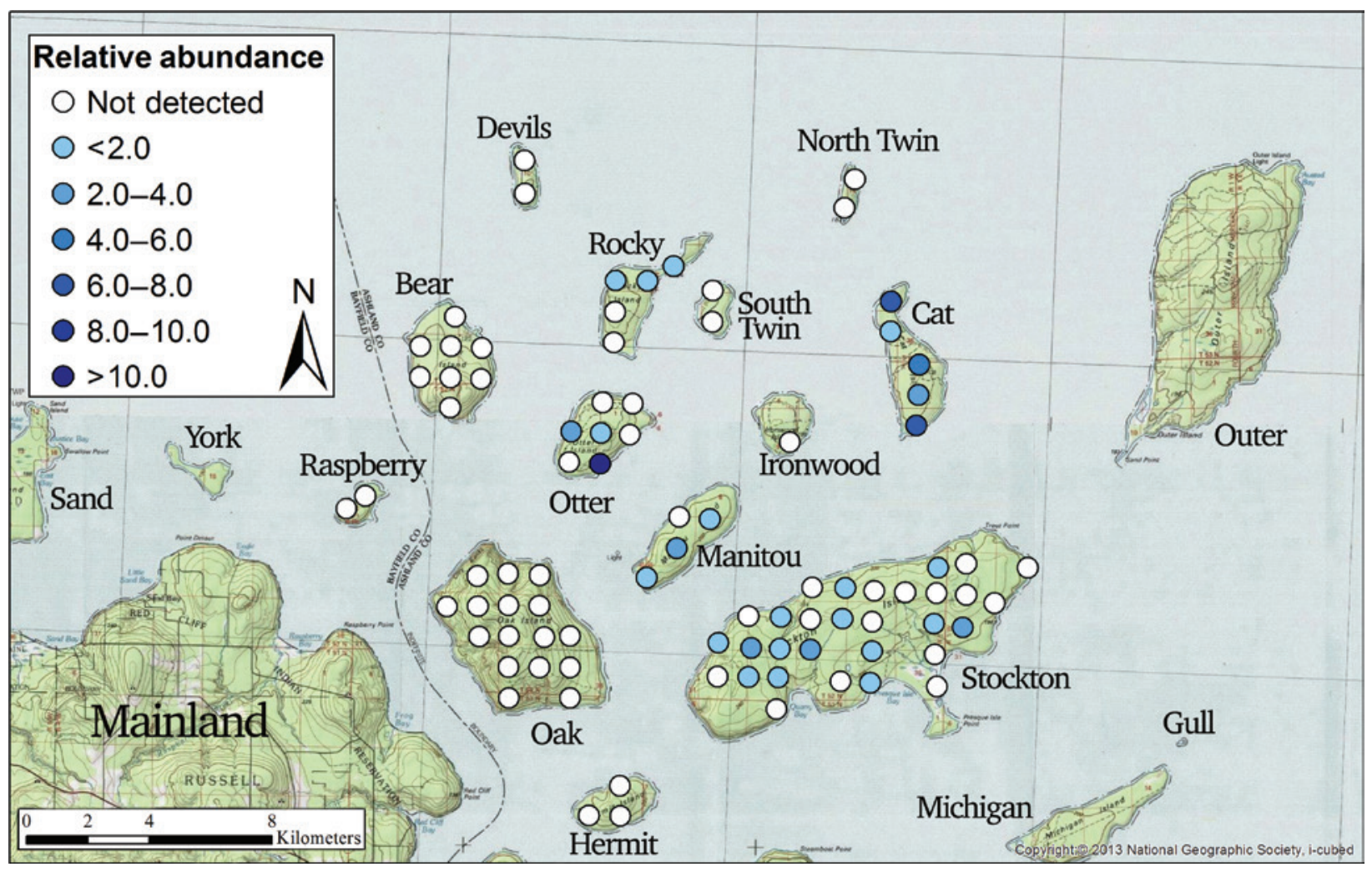

Figure 3: Distribution and relative abundance of American martens detected at camera trap sites on the Apostle Islands National Lakeshore, WI, USA from September 2014 to June 2016. 
(e.g. Levin 1992, Ruggiero et al. 1994). Carnivore richness at the island level appeared to be driven by resource limitation (island biogeography; MacArthur and Wilson 1967, Whittaker and Fernandez-Palacius 2007), while American marten presence at the island level appeared to be a combination of resource limitation (island size; MacArthur and Wilson 1967, Whittaker and Fernandez-Palacius 2007) and competitive interaction (human avoidance; Zielinski et al. 2008, Wang et al. 2015), and marten abundance at the site level appeared to be driven by competitive interactions (cascading carnivore interactions; Levi and Wilmers 2012, Allen et al. 2015). If studied alone, any of our three scales could give a biased understanding of the factors driving the system (e.g. Levin 1992, Ruggiero et al. 1994), but incorporating three levels of ecological scale, gave a more complete picture of the processes behind the abundance and distribution of the carnivore community in a temperate archipelago. Each island likely acts as a local community within the meta-community (Leibold et al. 2004), and communities should be relatively stable in any given moment due to the defined geographic limits of the island. However, it is likely the interaction of these processes on and among islands that move marten distribution and abundance towards an equilibrium (Hairston et al. 1960, Power 1992), and community dynamics will change over time as carnivore species colonize or become extinct from given islands.

Island biogeography is a critical theory in ecology, used to explain the distribution and abundance of wildlife species (MacArthur and Wilson 1967, Simberloff 1974, Whittaker and Fernandez-Palacius 2007). The effects of island biogeography on carnivore richness in APIS were pronounced, with higher richness on larger islands and lower richness as the distance from the mainland increased. This is an important confirmation that island biogeography is a powerful force in both temperate and inland island systems, as well as with complex mammalian species such as carnivores. Carnivore species in APIS may be dependent on periodic influxes from the mainland or larger islands to maintain their populations, due to demographic stochasticity and the genetic effects of small population size (Whittaker and Fernandez-Palacius 2007, Emerson and Gillespie 2008), as well as the difficulty of dispersal for terrestrial carnivores in island systems. Given the importance of island biogeography in this system, distance from the nearest island had less effect than might be expected (MacArthur and Wilson 1967, Whittaker and Fernandez-Palacius 2007). This is potentially because there was little variation in the distances between the islands that we studied (Supplementary material 1). Inter-island distance may become more important in the dynamics of the carnivore community in APIS in the future, however, as ice cover likely affects immigration and emigration, and a warming climate appears to be leading to declining ice cover in the system (Howk 2009).

The factors driving American marten presence and absence on islands was our most equivocal, and possibly most complex, ecological scale. This intermediate scale may be the most complex scale if it is where resource limiting (i.e. island size) and competitive interaction (i.e. human avoidance and direct competition with fishers) processes intersect. Island size is likely important as a measure of the resources available (MacArthur and Wilson 1967, Simberloff 1974); while human avoidance (Lesmesiter et al. 2015, Wang et al. 2015), and to a lesser degree direct competition (Zielinski and Duncan 2004, Fisher et al. 2012), were also important, and may interact with island biogeography in complex ways. This was evidenced by martens being absent from Oak Island, which is the second largest island in our study, but also very close to the mainland with a corresponding high human presence and substantial fisher abundance. The interaction of these processes may be responsible for martens more often being found on islands farther from the mainland, and potentially increasing the importance of immigration between islands for martens.

As a small carnivore, American martens are affected by competition with dominant sympatric competitors that exploit similar resources, most notably fishers (Zielinski and Duncan 2004, Fisher et al. 2012). At the camera trap site scale, the abundance of martens appears directly driven by competitive interaction processes but appears to be part of a behavioral cascade (e.g. Allen et al. 2015, Lesmesiter et al.2015), wherein coyotes appear to spatially limit fisher abundance and release martens from the competitive pressure of fishers. Our other model at the camera trap site scale with substantial support was human avoidance, and human avoidance and direct competition were also the important competitive interaction processes driving marten presence at the island level. These competitive interactions suggest that some aspect of an ecology of fear (Brown et al. 1999), where martens are affected by humans and dominant sympatric competitors (e.g. Fisher et al. 2012, Lesmesiter et al. 2015, Wang et al. 2015) seems to drive marten abundance at the site level.

The importance of resource limitation and competitive interaction processes varied depending on the ecological scale we studied (e.g. Levin 1992, Ruggiero et al. 1994). American martens are notable as the only state endangered mammal in Wisconsin (Woodford and Dumyahn 2011, Allen et al. 2018b), and our results show that it is important to account for multiple scales for effective 
management and conservation of species (e.g. Ruggiero et al. 1994). Our study was based on a small snapshot in time (2 years) that likely leads to a relatively stable system, however, studying the carnivore community over a longer time period could show trends in extirpation from and recolonization of islands (Simberloff 1974, Whittaker and Fernandez-Palacius 2007). It is important for future studies to move towards long-term monitoring to elucidate trends in carnivore community dynamics on the islands and mechanisms for how resource limitation and competitive interaction processes affect carnivore populations and communities over time in island systems.

Acknowledgments: This project was supported by the Apostle Islands National Lakeshore (GLNF CESU Agreement P14AC01180), Northland College (Department of Natural Resources; Sigurd Olson Professorship in the Natural Sciences; Morris O. Ristvedt Professorship in the Natural Sciences), and the University of Wisconsin (Schorger fund, Department of Forest and Wildlife Ecology; Beers-Bascom Professorship in Conservation). We thank students and technicians from the National Park Service, University of Wisconsin-Madison, and Northland College for their assistance with fieldwork.

\section{References}

Allen, M.L., L.M. Elbroch, C.C. Wilmers and H.U. Wittmer. 2015. The comparative effects of large carnivores on the acquisition of carrion by scavengers. Am. Nat. 185: 822-833.

Allen, M.L., M.J. Farmer, E.R. Olson, J. Van Stappen and T.R. Van Deelen. 2018a. Is there anybody out there? Occupancy of the carnivore guild in a remote temperate archipelago. Comm. Ecol. 19: 272-280.

Allen, M.L., B. Wojcik, B.E. Evans, E.E. lehl, R.E. Barker, M.E. Wheeler, B.E. Peterson, R.L. Dohm, M.A. Mueller, L.O. Olson, B. Ederer, M. Stewart, S. Crimmins, K. Pemble, J. Van Stappen, E. Olson and T.R. Van Deelen. 2018b. Detection of endangered American martens (Martes americana) in Apostle Islands National Lakeshore, Wisconsin. Am. Midl. Nat. 179: 294-298.

Brown, J.S., J.W. Laundre and M. Gurung. 1999. The ecology of fear: optimal foraging, game theory, and trophic interactions. J. Mammal. 80: 385-399.

Burnham, K.P. and D.R. Anderson. 2002. Model selection and multimodel inference: a practical information-theoretic approach. Springer, New York.

Carlson, J.E., J.H. Gilbert, J.W. Pokallus, P.J. Manlick, W.E. Moss and J.N. Pauli. 2014. Potential role of prey in the recovery of American martens to Wisconsin. J. Wildl. Manag. 78: 14991504.

Emerson, B.C. and R.G. Gillespie. 2008. Phylogenetic analysis of community assembly and structure over space and time. Trends Ecol. Evol. 23: 619-630.
ESRI. 2014. ArcGIS Desktop. Environmental Systems Research Institute, Redlands, CA.

Estes, J.A., J. Terborgh, J.S. Brashares, M.E. Power, J. Berger, W.J. Bond, S.R. Carpenter, T.E. Essington, R.D., Holt, J.B.C. Jackson, R.J. Marquis, L. Oksanen, T. Oksanen, R.T. Paine, E.K. Pikitch, W.J. Ripple, S.A. Sandin, M. Scheffer, T.W. Schoener, J.B. Shurin, A.R.E. Sinclair, M.E. Soulé, R. Virtanen, D.A. Wardle. 2011. Trophic downgrading of planet Earth. Science 333: 301-306.

Fisher, J.T., B. Anhold, S. Bradbury, M. Wheately and J.P. Volpe. 2012. Spatial segregation of sympatric marten and fishers: the influence of landscapes and species-scapes. Ecography 36: 240-248.

Gilbert, J.H., J.L. Wright, D.J. Lauten and J.R. Probst. 1997. Den and rest-site characteristics of American marten and fisher in Northern Wisconsin, p. 135-145. In: (G. Proulx, H.N. Bryant and P.M. Woodard, eds.) Martes: taxonomy, ecology, techniques, and management. Provincial Museum of Alberta, Edmonton, Alberta, Canada. p. 474.

Hairston, N.G., F.E. Smith and L.B. Slobodkin. 1960. Community structure, population control, and competition. Am. Nat. 94: 421-425.

Howk, F. 2009. Changes in Lake Superior ice cover at Bayfield, Wisconsin. J. Great Lakes Res. 35: 159-162.

Jackman, S. 2015. pscl: Classes and Methods for R Developed in the Political Science Computational Laboratory, Stanford University. Department of Political Science, Stanford University. Stanford, California. R package version 1.4.9. URL: http://pscl.stanford.edu/

Judziewicz, E.J. and R.G. Koch. 1993. Flora and vegetation of the Apostle Islands National Lakeshore and Madeline Island, Ashland and Bayfield Counties, Wisconsin. Michigan Botanist 32: 43-189.

Leibold, M.A., M. Holyoak, N. Mouquet, P. Amarasekare, J.M. Chase, M.F. Hoopes, R.D. Holt, J.B. Shurin, R. Law, D. Tilman, M. Loreau and A. Gonzalez. 2004. The metacommunity concept: a framework for multi-scale community ecology. Ecol. Lett. 7: 601-613.

Lesmesiter, D.B., C.K. Nielsen, E.M. Schauber and E.C. Hellgren. 2015. Spatial and temporal structure of a mesocarnivore guild in Midwestern North America. Wildl. Monogr. 191: 1-61.

Levi, T. and C.C. Wilmers. 2012. Wolves-coyotes-foxes: a cascade among carnivores. Ecology 93: 921-929.

Levin, S.A. 1992. The problem of pattern and scale in ecology. Ecology 73: 1943-1967.

MacArthur, R.H. and E.O. Wilson. 1967. The theory of island biogeography. Princeton University Press: Princeton, NJ.

Naing, H., T. Fuller, P.R. Sievert, T.O. Randhir, S. Htoo, S.H.T. Po, M. Maung, A.J. Lynam, S. Htun and W.N. Thaw. 2015. Assessing large mammal bird richness from camera-trap records in the Hukaung Valley of Northern Myanmar. Raffles Bull. Zool. 63: 376-388.

O’Connell, A.F., J.D. Nichols and K.U. Karanth, editors. 2011. Camera Traps in Animal Ecology: Methods and Analyses. Springer: New York, NY.

Oksanen, L. and T. Oksanen. 2000. The logic and realism of the hypothesis of exploitation ecosystems. Am. Nat. 155: 703-723.

Power, M.E. 1992. Top-down and bottom-up forces in food webs: do plants have primacy. Ecology 73: 733-746.

R Core Team 2016. R: A language and environment for statistical computing. R Foundation for Statistical Computing, Vienna, Austria. URL: https://www.R-project.org/. 
Ripple, W.J., J.A. Estes, R.L. Beschta, C.C. Wilmers, E.G. Ritchie, M. Hebblewhite, J. Berger, B. Elmhagen, M. Letnic, M.P. Nelson, O.J. Schmitz, D.W. Smith, A.D. Wallach and A.J. Wirsing. 2014. Status and ecological effects of the world's largest carnivores. Science 343: 1241484.

Ruggiero, L.F., G.D. Hayward and J.R. Squires. 1994. Viability analysis in biological evaluations: concepts of population viability analysis, biological population, and ecological scale. Conserv. Biol. 8: 364-372.

Simberloff, D.S. 1974. Equilibrium theory of island biogeography and ecology. Annu. Rev. Ecol. Evol. Syst. 5: 161-182.

Thompson, I.D., J. Fryxell and D.J. Harrison. 2012. Improved insights into use of habitat by American martens, p. 209-230. In: (K.B. Aubry, W.J. Zielinski, M.G. Rapahel, G. Proulx and S.W. Buskirk, eds.) Biology and conservation of martens, sables, and fishers: A new synthesis. Cornell University Press, Ithaca, NY. p. 580

Wang, Y., M.L. Allen and C.C. Wilmers. 2015. Mesopredator spatial and temporal responses to large predators and human development in the Santa Cruz Mountains of California. Biol. Conserv. 190: 23-33.
Whittaker, R.J. and J.M. Fernandez-Palacius. 2007. Island biogeography: ecology, evolution, and conservation. Oxford University Press, New York, NY. p. 416.

Wiscland 2.0 User Guide. 2016. Madison, WI, USA. URL: ftp://dnrftp01.wi.gov/geodata/landcover/wiscland2/user_ guide/Wiscland_2_User_Guide_September_2016.pdf.

Woodford, J.E. and S.L. Dumyahn. 2011. Conservation and management plan for American martens in Wisconsin. Wisconsin Department of Natural Resources, Madison, WI. p. 43.

Zeileis, A., C. Kleiber and S. Jackman. 2008. Regression models for count data in R. J. Stat. Softw. 27: 1-25.

Zielinski, W.J. and N.P. Duncan. 2004. Diets of sympatric populations of American martens (Martes americana) and fishers (Martes pennanti) in California. J. Mammal. 85: 470-477.

Zielinski, W.J., K.M. Slauson and A.E. Bowles. 2008. Effects of offhighway vehicle use on the American marten. J. Wildl. Manag. 72: 1558-1571.

Supplementary Material: The online version of this article offers supplementary material (https://doi.org/10.1515/mammalia-2017-0162). 